\title{
PALESTRA:
}

\section{ABEM e compromissos institucional e epistemológico: construindo uma área de conhecimento.}

Magali Oliveira Kleber

Inicialmente quero agradecer o convite para participar desse $3^{\circ}$ Encontro Regional Sul de nossa $A B E M$ e ao mesmo tempo, parabenizar a UDESC e a coordenação geral do evento, nas pessoas do Professor Sérgio Figueiredo e toda sua equipe, que não mediram esforços para viabilizar esta realização. Quero saudar também a todos participantes desse Encontro.

Quando me foi solicitado uma apresentação que buscasse resgatar o aspecto histórico dos Encontros Regionais da ABEM, tendo em vista que os dois primeiros Encontros foram realizados em Londrina, na minha gestão como Diretora Regional, a problemática para mim, concentrou-se em como abordar este tema, sem torna-lo linear, descritivo e enfadonho. Considerando que a nossa contemporaneidade tem apontado para nova ordem de organização cuja característica pode ser traduzida por termos como relação, integração, interligação, teia, rede, imaginei que a partir dessa concepção, haveria de achar, 
através de um exercício intelectual, uma conexão entre a tarefa de discorrer sobre as realizações da ABEM/Sul e o tema deste Encontro "Currículos de Música e Cultura Brasileira". Esta idéia foi também nutrida pela metáfora "linha e rede" conectada com metodologia na Educação Musical, desenvolvida no texto de Fonterrada (1997, p. 7-17). Este momento de reflexão, possibilitou-me retomar o caminho que percorremos nestes oito anos de $A B E M$ e pensar no que significou, neste processo, a realização dos Encontros Regionais, do ponto de vista institucional e político. Emergiu um primeiro ponto da rede que eu queria tecer, com a constatação da intersecção institucional entre a $A B E M$ e a Universidade, uma vez que todos os Encontros Nacionais e a maioria dos Encontros Regionais, já realizados, foram ancorados pelas Universidades das respectivas cidades onde ocorreram estes eventos. Notei também que os dois Encontros Regionais já anunciados para este ano, estarão acontecendo no âmbito da Universidade. Portanto, não é por acaso que este terceiro Encontro Regional-Sul está acontecendo na Universidade Estadual de Santa Catarina. Esta é, na verdade, uma condição historicamente determinada. . Assim, pensei em organizar a minha fala a partir da ótica que percebe a $A B E M$ vinculada simbióticamente à Universidade, . Dessa forma poderia estabelecer uma conexão entre a história dos Encontros Reginal/Sul da $A B E M$ e a Universidade, e então tecer uma rede 
que integrasse estas duas instituições com Currículo e a Cultura Brasileira.

Como sabemos, desde que foi fundada em 1991, em Salvador- Bahia, a ABEM vem realizando um trabalho importantíssimo de sedimentação da área de Educação Musical no país, o que vem resultando em uma positiva mobilização da área e na conquista de espaços políticos significativos. O reflexo disso pode ser observado, por exemplo, nas quantidade e qualidade de suas publicações, na participação da CAPES, apoiando nossos Encontros ao longo desses anos, e também participação da área nos recentes trabalhos realizados pela Comissão de Especialistas do Ensino das Artes e Design (CEEARTES), com vistas à reformulação curricular dos cursos de graduação em Artes, tendo inclusive a Dra. Alda de Oliveira na presidência dessa Comissão.

Nesse oito anos de existência percebeu-se a necessidade de se regionalizar as discussões de maneira que se oportunizasse um trabalho mais localizado, considerando-se as dificuldades geradas pela dimensão do nosso país. Os Encontros Regionais, estariam assim antecipando a discussão do tema proposto para - Encontro Anual, propiciando o aprofundamento do debate, além de possibilitar encaminhamentos que atendessem as especificidades e necessidades de cada região .

A Região Sul teve o privilégio de realizar o primeiro Encontro Regional, em julho de 1997, em Londrina, e teve portanto, o objetivo de 
dinamizar o trabalho da ABEM e estabelecer estratégias para promover, de fato, uma maior integração os Estados do Paraná, Santa Catarina e Rio Grande do Sul, visando uma maior divulgação e o fortalecimento de nossa Associação nesta região. 0 Encontro aconteceu, inserido da programação do 6o. Simpósio Paranaense de Educação Musical, realizado de 30 de junho a 04 de julho de 1997 , com a temática "O Ensino da Música diante de Novos Paradigmas", organizado pela Área de Música da Universidade Estadual de Londrina. O Encontro discutiu questões ligadas à nossa contemporaneidade, considerando a necessidade de se repensar a Educação Musical frente ao avanço científico e tecnológico e sua decorrência no contexto social, cultural e econômico. Abordou -se a necessidade de uma atuação política da $A B E M$ neste momento de implementação da nova LDB, estabelecendo-se uma real integração entre nossa Associação e as escolas de $1^{\circ}$ e $2^{\circ}$ graus da rede pública, escolas de música, conservatórios. Eis aqui também, um ponto nevrálgico presente na demanda da Universidade: a necessidade de uma efetiva articulação e integração entre os diferentes espaços institucionais e comunitários no qual esta se insere Espera-se que esta Instituição justifique sua existência perante a sociedade, pela competência e qualidade com que desenvolve suas atividades de ensino, pesquisa e extensão, cujos objetivos maiores buscam despertar e aguçar o espírito crítico, expandir as fronteiras do conhecimento científico, artístico 
e tecnológico e, promover a melhoria da qualidade de vida da comunidade da qual faz parte.

O II Encontro Regional-Sul da ABEM, promovido juntamente com a área de música do Departamento de Arte/Universidade Estadual de Londrina (UEL) e o $18^{\circ}$ Festival de Música de Londrina, abordou o tema "Propostas da IES da Região Sul do Brasil para a Diretrizes Curriculares dos cursos de graduação em Música", nos dias 04 e 05 de maio de 1998, na UEL. Participaram como palestrantes as professoras Dra. Vanda Freire, Presidente da ABEM, Dra. Alda de Oliveira, Presidente CEEARTES e Dra. Liane Hentschke., membro representante da área de música nesta Comissão. As Instituições de Ensino Superior representadas neste Encontro foram a Universidade Federal do Rio Grande do Sul, Universidade Estadual de Santa Catarina, Faculdade de Artes do Paraná, Escola de Música e Belas Artes do Paraná e Universidade Estadual de Londrina. Do Encontro resultou um documento oficial elaborado pelo grupo e enviado à Comissão de Especialistas em Artes/Música, MEC/SESu, com sugestões para a formulação do documento referente a essas Diretrizes Curriculares. A partir das discussões, foi consenso do grupo que a educação universitária deve estar "comprometida com a questão da competência na formação intelectual de seus aluno, tanto quanto com a formação política, mediante a conscientização crítica dos processos inerentes ao exercício da 
cidadania". O documento defende uma concepção progressista de educação para fundamentar uma proposta curricular e, nesta perspectiva aborda outros ponto como o perfil desejado do formando, competências e habilidades desejadas e conteúdos obrigatórios. Novamente, ao tratar de questões inerentes ao âmbito de sua competência e responsabilidade a partir da reflexão e da discussão, a ABEM revelou uma preocupação em se posicionar frente à condução da Educação Musical no país.

Ao pousar o olhar sobre estes eventos, vemos que há uma consistência que imprime à ABEM um perfil institucional e político comprometido com a formação do indivíduo e a construção/produção do conhecimento musical. Ao consideramos ainda, a curta existência de nossa Associação, este perfil reflete uma trajetória também consistente e significativa. Penso que esta característica também não se dá por acaso, mas pela própria relação da ABEM com a Universidade, relação esta construída por aqueles que delineiam os encaminhamentos dessa Associação e estão, de alguma forma, ligados a Universidade. Esta estreita relação leva-nos a pensar na função social que invoca estas duas instituições no contexto da sociedade contemporânea. Ao se focalizar o compromisso dessas duas instituições com a formação do indivíduo e a construção/produção do conhecimento, projeta-se também a necessidade de se rever as formas de pensar, sentir e agir, considerando a multiplicidade e a complexidade do cenário atual. Ao se 
reconhecer a instalação de uma nova ordem na dinâmica da comunicação e seus efeitos no processo de globalização, torna-se premente uma reflexão acerca das tensões que se confrontam nesta nova configuração de mundo. A tensão entre o global e o local, entre o universal e o singular, entre a tradição e a modernidade tangem a problemática que se configura na busca da preservação de uma identidade e na necessidade de cada ser humano tornar-se cidadão do mundo (DELORS, 1999, p.13). É certo que os paradigmas convencionais não mais atendem aos apelos de um novo tempo, que se nos impões sob o signo da comunicação e da informação. A educação na sociedade contemporânea representa um poderoso instrumento de integração dos sujeitos no universo do trabalho, no universo das relações sociais e no universo da cultura simbólica.

Neste contexto, espera-se hoje da Universidade um resgate do seu papel enquanto locus da produção do saber, a partir de um modelo includente, no qual se leve em conta as relações sociais envolvidas na construção do conhecimento. Assim, é preciso tocar na questão das relações sociais de poder implícitas nesse processo, para que se possa discutir a problemática da desigualdade social e sua relação com a educação. É preciso que se considere os conflitos, as contradições, as inclusões e as exclusões que acoplam ou dividem os grupos sociais. 
Do ponto de visto do estudo do currículo esta problemática se reflete na possibilidade do currículo produzir significados simbólicos sociais, os quais incidem na construção de identidades individuais e sociais (Silva, 1995, p.198). O currículo enquanto "artefato cultural" e uma forma contemporânea de organizarmos o conhecimento e o saber com vistas a sua transmissão (Moreira e Silva, 1995; Goodson, 1995; Silva, 1999) veicula, através de um conhecimento corporificado, imagens, narrativas, estórias, culturas dos diferentes grupos sociais e sobre os diferentes grupos sociais. Cataliza no seu entorno a possibilidade de instituir identidades hegemônicas, legitimando ou marginalizando grupos sociais, através de uma associação tácita com sua produção cultural. Esta concepção curricular repousa na relação entre a escola, enquanto agente de socialização, e o currículo, reconhecido em sua dupla face, ou seja, "um explícito e formal e outro oculto e informal" (Giroux, 1993, p. 69). Ao se negar a neutralidade social e política do currículo, expõe-se no seu reverso, sua ligação com questões relacionadas com o poder e o controle na sociedade, com vistas a legitimação da "reprodução social e cultural de relações de classe, raça e gênero na sociedade dominante". Esta questão, focalizada no âmbito específico da educação musical, remete-nos para a sua condição de subordinação ao "etnocentrismo musical, que leva como base fundamental a crença de que a música de tradição 
culta/erudita dos grupos dominantes é a única digna de estudo e apreciação." (Béhague, 1998, p. 26). Não se quer aqui negar a importância da tradição da música européia ocidental e, muito menos o seu valor, mas sim, questionar o estereótipo a ela atribuído como a "música culta", em detrimento de manifestações musicais de outras culturas. Em relação, por exemplo, à música latino-americana, a música européia "representa e sempre representou uma elite bem definida dos grupo sociais de maior poder político e econômico" (Béhague, 1998, p. 29). Ao se pensar no tema desse Encontra, levanta-se a necessidade de nós, professores de música, estabelecermos uma maior aproximação da cultura brasileira com os processos educacionais, sejam eles formais ou informais. É preciso que se estabeleça uma real aplicação do nosso patrimônio cultural no processo de construção do conhecimento musical. Para tanto, é preciso tocar num ponto doloroso: nossa formação nos permite desenvolver com uma certa competência esta proposição?

Outra questão, entre muitas, diz respeito à busca de um novo modelo curricular que rompa com a fragmentação do conhecimento resultante de uma concepção linear e compartimentalizada, fruto da racionalidade positivista, na qual a divisão, a hierarquização, a linearidade são os pressupostos a serviço da eficiência e produtividade. Assim, as noções de conhecimento que permeiam grande parte dos currículos atuais estão em descompasso com as modificações sociais, com as profundas 
transformações na natureza e na extensão do conhecimento e nas formas de concebê-los. A produção do conhecimento deve contemplar a multidirecionalidade, a interdisciplinaridade, a hipertextualidade (Pires, 2000, p.190), instrumentalizando o indivíduo para atuar de forma criativa em situação imprevisíveis. Para Oliveira (1997, p.31), a concepção de currículo em música deve contemplar uma visão contextualizada, propiciando aos indivíduos tenham "oportunidades concretas, no seu cotidiano, de absorver músicas das mais diversas formas, estilos, gêneros, países, compositores e culturas, abrindo-se, assim para uma forma ultra dimensionada, potencializada pelos avanços da comunicação e tecnológicos. A concepção de um currículo em música contextualizado é defendido por David Elliot, citado por Oliveira (ibidem, p.31):

"currículo em música deve estar centralmente voltado à organização do ensino $e$ da aprendizagem contextualizada. nesta visão da práxis, educação musical é um problema de induzir estudantes em formas de vida musical: de aprofundar o envolvimento dos alunos em culturas musicais selecionadas através da audição sedimentada no fazer musical reflexivo autêntico, artístico e crítico, o que significa: executar-ouvir, improvisarouvir, compor-ouvir, arranjar-ouvir $e$ reger-ouvir".

A ABEM ao enfocar, nesse III Encontro, o tema relativo Currículo e Cultura revela uma 
preocupação com a problemática que envolve os diferentes níveis da educação brasileira na busca de superar os desafios na formação de homens e mulheres para o exercício de uma cidadania plena, onde os sujeitos sejam contemplados na suas dimensões individual e social. Assim também se coloca a Universidade Pública Brasileira, no seu compromisso com as novas demandas da sociedade contemporânea as quais exigem uma "formação que articule, com organicidade, a competência científica e técnica, com a inserção política e postura ética". .compromisso com a construção de uma sociedade, na qual se prevaleça a dignidade humana como direito universal.

Ao se pensar em propostas para o desenvolvimento do nosso trabalho, enquanto uma Associação de profissionais da Educação, é imprescindivel reconhecer a singularidade 4 desse momento que aponta a necessidade de uma maior e efetiva vinculação da área com a suas funções sócio-política, uma vez que, tanto a ABEM como a Universidade Pública transitam por um sistema complexo, que é o da Educação, com profundas implicações sociais e políticas. Faz-se necessário, nesse momento, atitudes concretas que respondam às questões relacionadas com construção de um currículo em musica comprometido com a preparação de indivíduos para uma nova ordem social e que rompa com modelos pedagógicos e metodológicos que perpetuam valores que não mais respondem à necessidades de nossa contemporaneidade. Para que não se represe no 
discurso, esta questão, implica em rever nossa prática, enquanto educadores, e assumirmos uma posição de risco, que contempla junto com a ousadia, o imprevisível, a incerteza, momentos de angúsita. Romper com velhos paradigmas curriculares e construir novos seria uma ousada empreitada nesse tempo de transformações.

\section{Referências Bibliotráficas}

BÉHAGUE, G. Para uma educação musical realista na América Latina ou A contribuição etnomusicológica na formação realista do educador musical latino americano. Anais do I Encontro Latino-Americano de Educação Musical / VI Encontro Anual da ABEM, Salvador, 1998, p. 26-31.

DELORS, J. Educação : um tesouro a descobrir. Relatório para a UNESCO da Comissão Internacional sobre educação para o século XXI. São Paulo : Cortez; Brasília, DF : MEC : UNESCO, 1999.

FONTERRADA, M. A linha e a rede. Anais do $1^{\circ}$ Encontro Regional Sul da ABEM/ $6^{\circ}$ Simpósio parananense de Educação Musical. Londrina, 1997, p. 7-17.

GIROUX, H. Teoria Crítica e Resistência em Educação. Trad. Ângela M. Biaggio. Petrópolis, RJ : Vozes, 1986. 
GOODSON, I. F. Currículo: Teoria e História. Trad. Atílio Brunetta. Petrópolis, RJ :

Vozes, 1995.

MOREIRA, A. F. e SILVA, T.T. (orgs) Sociologia e Teoria Crítica do Currículo: uma introdução. In : Currículo, Cultura e Sociedade. São Paulo : Cortez, 1995, p. 7-37.

OLIVEIRA, A. Construção da Memória Musica do Indivíduo. Anais do I Encontro Latino-Americano de Educação Musical / VI Encontro Anual da ABEM, Salvador, 1998, p. 28-36.

PIRES, C. M. C. Currículos em Matemática: da organização linear à idéia de rede. São Paulo : FTD, 2000.

SAVIANI, D. Ensino Público e algumas falas sobre universidade. São Paulo : Cortez : Autores Associados, 1991.

. SILVA, T. (org.) Currículos e Identidade Social: Territórios Contestados. In : Alienígenas na sala de aula. Petrópolis: Vozes, 1995, p. 190-207.

. Pedagogia Crítica em tempos pós-

modernos. In: identidades Terminais.

Petrópolis, RJ :Vozes, 1996, p. 137-159.

Identidades Terminais : as

transformações na política da pedagogia e na pedagogia na pedagogia política. Petrópolis, RJ : Vozes,1996b.

. Documentos de Identidade : uma

introdução às teorias do currículo. Belo Horizonte : Autência, 1999. 
SOUZA, J. Contribuições teóricas e metodológicas da Sociologia para a pesquisa em Educação Musical. Anais do $5^{\circ}$ Encontro Anual da ABEM, Londrina, 1996, p. 61-74. - O conceito de cotidiano como perspectiva para a pesquisa e a ação em educação musical. Anais do I Encontro Latino-Americano de Educação Musical / VI Encontro Anual da ABEM, Salvador, 1998, p. 38-44.

TOURINHO, I. Considerações Sobre a Avaliação de Método de Ensino de Música. Anais do III Encontro da ABEM. Junho, 1994, p. 13-43. 